\title{
Proposal Technique for an Static Var Compensator
}

\author{
${ }^{1}$ V.N.Ganesh, ${ }^{2}$ S.Periasamy, ${ }^{3}$ D.Sivakumar, \\ EEE department, Assistant professor, SRM University, \\ EEE Department, Assistant professor, SRM University, \\ EEE Department, Assistant professor, SRM University,
}

\begin{abstract}
This paper deals with the preliminary design of an SVC, which is the most important part of the design process, because any specific error in the preliminary design and specifications in requirements documents may end up with great amount of money, labour and time loss. The following subjects have to be investigated thoroughly in order to finalize the preliminary design of an SVC. In this paper the following parameters like Single thyristor operation, Series thyristor operation, Single Piece / Two Pieces Reactor Arrangements are considered for the design procedure and the fault cases simulated in PSCAD concerning three phase connections.
\end{abstract}

\section{Introduction}

Power quality of the supply busbar is determined by field measurements. The standards concerning power quality and SVCs should be investigated in order to define and consider any power quality issues. Currently valid regulations for reactive energy limits and other power quality issues may differ from one country to another.

\subsection{Load Characteristics}

Whenever a TCR based SVC project is initiated, it is necessary to define the load characteristics clearly. The precise load characteristics are evaluated by using: Field measurement by data acquisition, Monthly electrical energy bills. Flicker performance, shunt filter and reactor sizing depend on these variations. If the load is varying slowly, the control system design does not have a great impact on the design. Duty cycle and load unbalance also plays a significant role in the design. The negative sequence compensation is a challenge in TCR design as mentioned in [1,2]. The methodology of load identification is also advised in the standards [3] for Transmission SVCs.

\subsection{Project Requirements}

The customers may require some flexible solutions because of the future plans for the enterprise that the SVC is installed. Capacity of the plant may change so that a modular/flexible SVC may be required instead of a fixed installation capacity.

\subsection{Environmental and Operational Conditions}

The following environmental conditions are needed to be considered for the robustness of the SVC installation: Maximum and minimum values of ambient temperature, Humidity, Snow load, Pollution level

\subsection{Design of the Power Stage \\ 1.4.1 Single Thyristor Operation}

The Thyristor is the "static switch" part of a TCR based SVC. The current flowing through the reactors is adjusted by thyristor valves. They are connected back-to-back and may share the same snubber. Selection of the thyristors and snubbers depends on many parameters. In order to verify the selection, a computer simulation is appropriate. In Fig.1.1, a typical thyristor valve can be seen. A thyristor needs to be triggered into conduction, therefore the electronic triggering circuit design is also important as well as the thyristor selection. Some failures may occur if triggering circuit is not designed carefully. A detailed thyristor selection analysis can be found in [5]. In order to be able to select the thyristors, the following information in thyristor data sheets, such as the one in[6], should be investigated: 


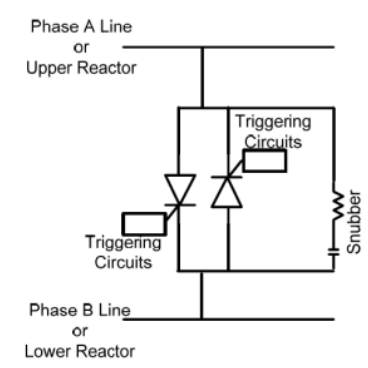

Fig1.1 A typical back to back connected thyristor valve

\subsubsection{Reverse Blocking Voltage and Off state}

$\mathrm{V}_{\text {DRM }}$ is the repetitive peak off state voltage and $\mathrm{V}_{\text {RRM }}$ is the repetitive peak reverse voltage. $\mathrm{V}_{\text {DRM }}$ and $\mathrm{V}_{\mathrm{RRM}}$ can be different from each other according to the thyristor selected.

\subsection{3 di/dt and $\mathrm{dv} / \mathrm{dt}$}

During the triggering of the thyristor, the region of the gate connection carries the thyristor current and then spreads over the whole wafer area. In order to avoid excessive dissipations during this operation, the amplitude of this current should be limited. di/dt is defined for the switching instants, and once the conduction starts, it is not limited to a specific value. Operating frequency, peak value of permissible on state current for half sine wave, gate triggering current and the rate of rise of gate current are given in datasheets for the definition of di/dt. If the $\mathrm{dv} / \mathrm{dt}$ value defined by the producers is exceeded, the thyristor self triggers which lead to a break down in the wafer. Therefore, $\mathrm{dv} / \mathrm{dt}$ should be limited to a safe value by using passive devices such as snubbers.

\subsubsection{Cooling Method}

Cooling method is selected according to the level of power dissipation and available resources. The major cooling types are: Natural air cooling, Forced air cooling and Liquid based cooling (de-ionized water or other coolant). Heatsink selection depends on the cooling method. The heatsinks carry the thyristor current; therefore they are selected from good electrical and heat conducting materials, usually aluminum or copper.

\subsubsection{Thermal Considerations}

Theoretically, a TCR produces reactive power only. However in the practical implementation, there are many sources of dissipation. In addition to the copper losses of reactor banks, thyristor stack is also source of dissipation, not only because of the voltage drop on the thyristors, but also because of the passive elements connected to the stack. The main sources of dissipation can be classified as: Thyristor losses (conduction, switching and off state losses), Snubber losses, Equalizing resistor losses, Valve reactor losses (if present), Protection circuit losses, Gate triggering circuit losses, Bus bar or cable losses

The method of calculating the thyristor valve losses are defined in [4] Annex C. In this standard, however protection circuit, gate triggering circuit and bus bar losses are omitted in the calculation of thyristor valve losses because in high power applications these issues are negligible. Therefore, thyristor valve total power loss, $\mathrm{P}_{\text {valve }}$, is given in [4] as:

$$
\mathrm{P}_{\text {value }}=\mathrm{P}_{\text {cvalve }}+\mathrm{P}_{\text {Tsw }}+\mathrm{P}_{\text {vd }}+\mathrm{P}_{\text {sn }}+\mathrm{P}_{\text {hyst }}(1.1)
$$

$\mathrm{P}_{\text {cvalve }}$ is thyristor valve conduction losses, $\mathrm{P}_{\text {Tsw }}$ is thyristor total switching losses, $\mathrm{P}_{\text {vd }}$ is equalizing losses, $\mathrm{P}_{\text {sn }}$ is snubber circuit losses, and $\mathrm{P}_{\text {hyst }}$ is reactor (hysteresis) losses. Prolonged thermal stress on the thyristors is not desired. The effects of such thermal stress can lead to thermal fatigue, or an earlier failure of the thyristor, which is discussed in [9].

\subsubsection{Snubber Circuit}

The series inductance of the circuit, combined with the rate of rise of the current, produces transient voltage peaks across the thyristor terminals. If voltage exceeds the thyristor ratings, it may lead to the destruction of the device permanently. Therefore, in order to dampen the voltage overshooting a parallel R-C snubber circuit is connected as a general practice [1].

The snubber values are usually selected to keep the circuit response critically damped. Increasing the damping level leads to more dissipation. A detailed snubber design can be found in [5]. 


\subsubsection{Triggering Circuit}

Triggering circuits usually have dual tasks, primarily isolation and secondarily supplying the gate current necessary to switch on the thyristor. The isolation can be achieved by magnetically or optically. Pulse transformers suitable for transmitting high current and high frequency pulses are may be used for magnetic isolation. In medium voltage applications pulses are usually transmitted to the gate by a ferrite core placed around a single wire carrying the low voltage side current. There is isolation material around the primary conductor.

Optical isolation is achieved through optical fibres (F/O). However triggering circuit with $\mathrm{F} / \mathrm{O}$ requires a gate energy circuit in order to be able to supply the current pulse necessary for the gate.

\subsubsection{Overvoltage protection}

Overvoltage in an SVC system usually occurs in a temporary fault condition such as a lightning surge. Temporary overvoltage cases needs fast interaction and protection, therefore they are handled by the overvoltage protection circuits which are usually placed in or near the thyristor triggering circuits. In a series thyristor operation, equalizing resistor circuits or some of the series thyristors may breakdown. This may impose overvoltages on the remaining of the valve circuit. Overvoltage protection triggers rest of the thyristors to conduction thus protecting them against the overvoltage.

Breakover diodes (BOD), avalanche type diodes or metal oxide varistors (MOV) are used in overvoltage protection circuits. Such implementations can be found in [7] with a BOD, and in [5] with a MOV. Continuous operating voltages may sometimes rise above the standard levels defined in [8]. If such an overvoltage occurs, the control system must react to this type of fault.

\subsection{Series Thyristor Operation}

Series thyristor operation requires additional design work. Connecting semiconductor devices in series or in parallel requires special attention on voltage and current sharing. A failure in balancing the current or voltage may lead to the failure of the whole stack.

Design and implementation of series operation of thyristors are discussed in [5]. The same design is also used in the utilization of the ISDEMIR ladle furnace compensation system. In Fig.1.2 the seriesconnected thyristors are seen. Cooling water flows through the heatsinks, not only cooling the thyristors but also cooling the snubber circuits. The operation voltage of $6.3 \mathrm{kV}$ requires special attention to the insulation. The distance between the high voltage switches and other equipment is selected by considering the safe values and pulse transformers are placed at the back of the insulating separator thus avoiding flashovers to the control circuit.

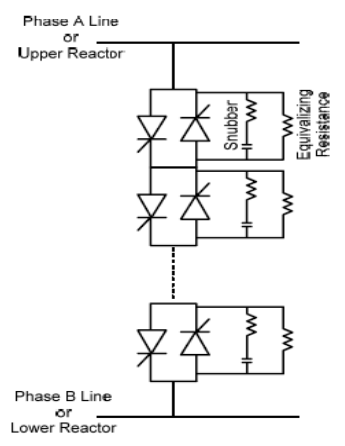

(a)

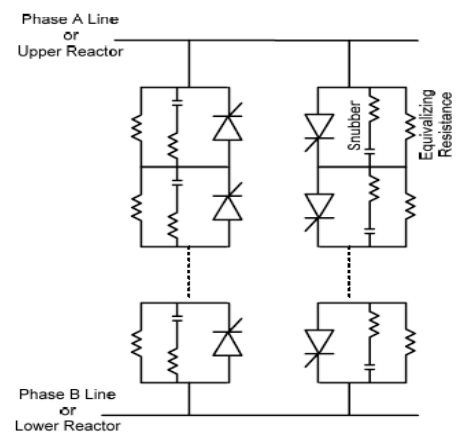

(b)

Fig.1.2 A thyristor stack which consists of series connected thyristors. (a): with antiparallel connected switches. (b) with positive and negative thyristors grouped

\subsection{Single Piece / Two Pieces Reactor Arrangement}

In order to protect the Thyristor valves against a short circuit, the reactors can be divided into two series reactors having the same total phase reactance. Connecting the Thyristor valves in between these series reactors will limit the maximum fault currents. If one reactor is short circuited, the fault current will be limited. If phase is short circuited, no fault current will flow through thyristors. In order to observe a total short circuit current, each reactor placed on top of one another should be separately short circuited, which has a very low probability in a TCR installation because of the geometry. 


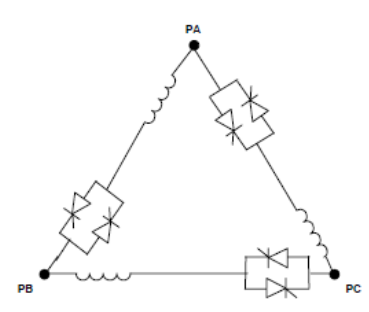

(a)

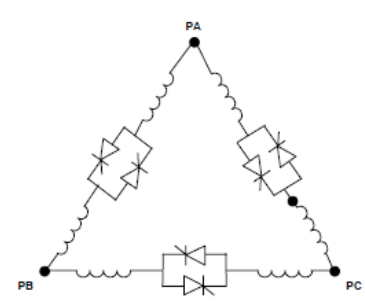

(b)

Fig.1.3 Reactor arrangement; (a) Single piece, (b) two pieces

Several fault cases that can appear in a delta connected TCR are given in Fig. 1.4, 1.5 and 1.6. These cases are simulated for a $1 \mathrm{kV}$ 1,5 MVAr TCR + 0,75 kVAr Filtre installation with a short circuit $525 \mathrm{MVA}$. Filters consist of three 5 harmonic and three 7 harmonic tuned filters at $1 \mathrm{kV}$ side. A feature of PSCAD called "Multirun" is used for multiple simulations. The results are given in Table 1.1. The worst case is found to be a short circuit across the upper or lower piece of the reactor.

$$
\begin{aligned}
& \text { (1) - }
\end{aligned}
$$

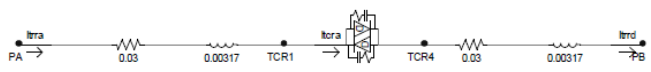

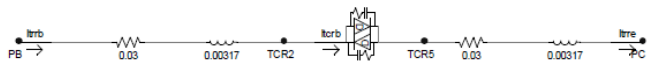

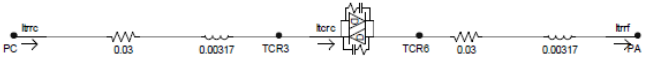

Fig.1.4 PSCAD Multirun (Multiple Simulation) for different fault types

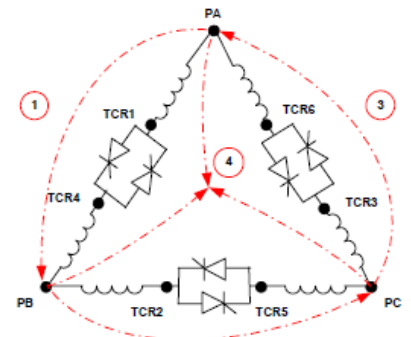

(2)

Fig.1.5 Fault cases simulated in PSCAD concerning three phase connections

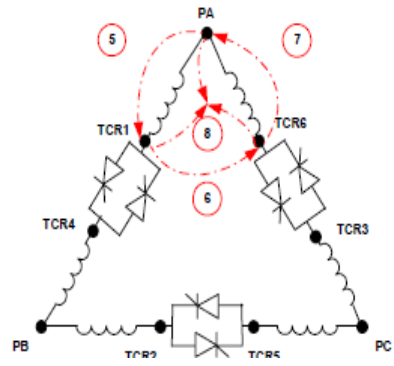

Fig.1.6 Fault cases simulated in PSCAD concerning one phase and two thyristor terminal connections belonging different phases

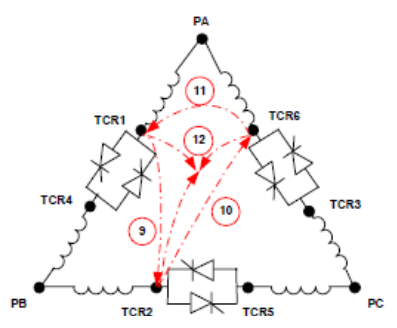

Fig.1.7 Fault cases simulated in PSCAD concerning three thyristor terminals belonging different phases

Table.1.1. PSCAD Multirun simulation results

\begin{tabular}{|l|l|l|l|l|l|l|}
\hline $\begin{array}{l}\text { Cas } \\
\mathrm{e}\end{array}$ & $\begin{array}{l}\text { Maximum 5th } \\
\text { Harmonic Filter } \\
\text { Current (kA) }\end{array}$ & $\begin{array}{l}\text { Maximum 5th } \\
\text { Harmonic Filter } \\
\text { Capacitor } \\
\text { Voltage (kV) }\end{array}$ & $\begin{array}{l}\text { Maximum 7th } \\
\text { Harmonic Filter } \\
\text { Current (kA) }\end{array}$ & $\begin{array}{l}\text { Maximum 7th } \\
\text { Harmonic Filter } \\
\text { Capacitor } \\
\text { Voltage (kV) }\end{array}$ & $\begin{array}{l}\text { Maximum TCR } \\
\text { Line Maximum TCR } \\
\text { current }\end{array}$ & $\begin{array}{l}\text { Thyristor } \\
\text { current (kA) }\end{array}$ \\
\hline 1 & 0,4760 & 0,9582 & 0,4296 & 1,0245 & 26,7383 & 0,7590 \\
\hline 2 & 0,1383 & 0,5457 & 0,0927 & 0,5009 & 33,7312 & 0,9013 \\
\hline 3 & 0,1276 & 0,8337 & 0,0832 & 0,8152 & 27,5715 & 0,7833 \\
\hline 4 & 0,2920 & 0,4659 & 0,2629 & 0,4559 & 39,4042 & 0,6918 \\
\hline 5 & 0,1333 & 0,8257 & 0,0877 & 0,8005 & 1,4378 & 1,6126 \\
\hline 6 & 0,1260 & 0,8171 & 0,0826 & 0,7959 & 1,7268 & 1,8834 \\
\hline 7 & 0,1277 & 0,8336 & 0,0832 & 0,8151 & 1,0207 & 1,0602 \\
\hline 8 & 0,1300 & 0,8090 & 0,0855 & 0,7799 & 2,5117 & 1,8673 \\
\hline 9 & 0,1266 & 0,8253 & 0,0828 & 0,8054 & 1,1658 & 1,1886 \\
\hline 10 & 0,1277 & 0,8336 & 0,0832 & 0,8151 & 1,0207 & 1,0602 \\
\hline 11 & 0,1303 & 0,8294 & 0,0853 & 0,8070 & 1,0265 & 0,7659 \\
\hline 12 & 0,1281 & 0,8252 & 0,0836 & 0,8029 & 1,2619 & 1,0690 \\
\hline
\end{tabular}




\subsection{Reactor Design}

Reactor design for the SVC TCR and shunt filters require special attention to current harmonics and voltage harmonics levels because dissipations in the reactors may be higher than the standard shunt reactors. The Standard IEC 289 [15] gives the definitions and suggestions for shunt reactors. IEEE standards [10-14] give detailed information on reactors and their requirements. IEEE Std C57-120-1991 [14] contains the loss calculations while [12] proposes the test procedures for reactors.

The following should be conducted by the customer to the manufacturer when a reactor is to be designed: Standard (generally IEC 60289), air-cored / iron cored, Frequency, Rated voltage (line-line or phase, rms, default IEC 38), Max.continuous operating voltage (kV), Rated inductance per phase ( $\mathrm{mH})$, Rated continuous current (kA), Max. continuous current (kA), TDD, Short circuit power before reactor, Outdoor/indoor installation, Insulation class, Cooling type, Maximum ambient temperature, Tuning frequency (If connected in a shunt filter, Hz), Quantity and construction details (including terminal connections and mounting style such as top-to-top or independent). The reactor ratings should be verified by a power system simulation tool. In the simulation, worst case scenarios such as misfiring (where conduction per thyristor is longer than 180o) and short circuits can be investigated. The manufacturers determine the minimum safe distance to other magnetic material and closed loop conductors. These magnetic clearances around the reactor depend on the individual reactor design and. should be taken into account in the layout of the overall system.

\subsection{Harmonic Filter Design}

The SVC topology is important in the decision for filtering. The complete SVC topology should be selected before starting the frequency response analysis.

\subsubsection{Frequency Response of the Filters}

Thyristor controlled reactor (TCR) acts as a harmonic current source and produces its own odd

harmonic current components $\left(3^{\text {rd }}, 5^{\text {th }}, 7^{\text {th }}, 9,11^{\text {th }}\right.$, etc.) for symmetrical triggering in the steady-state. However, during control, firing angle will change from positive half-cycle to negative half-cycle resulting in production of even harmonics $\left(2,4^{\text {nd }}\right.$, etc.). These even harmonics are taken as temporary overloads on filter reactors and capacitors. In a delta connected TCR, triple harmonics do not appear in the line currents for symmetrical triggering in the steady state. They will circulate through the delta connected reactor bank. However, in transient state owing to control, unbalanced portion of triple harmonics will be reflected to the line side. These temporary overloads on filter elements are taken into account by safety margins in the design. An important phenomenon of TCR operation during firing angle control from positive half-cycle to negative half-cycle is the generation of direct current component. This may move the magnetic operating point on the B-H characteristics of SVC transformer and thyristor controlled reactors for the iron core case. Therefore, the linearity of TCR core is essential for iron-core solution. Simulations should be carried out according to this assumption in order to find out harmonic loadings on filter elements. Filter circuits can be designed according to the rules described in IEC 61642 [16]. The loads are taken as harmonic current sources in simulation, which inject $1.0 \mathrm{~A} \mathrm{rms}$ at all harmonic frequencies.

\subsection{TCR Control}

Thyristor controlled reactor is a variable susceptance that can be controlled by triggering delay of the thyristor gate signals. The control system varies according to the desired method of TCR implementation. These methods are discussed in the below section.

\subsection{Control System Overview}

Control system that is only designed for reactive power compensation is a simple controller that calculates the necessary firing angle of each phase. It is also acceptable if all three phases are fired with the same angle. This type of control achieves reactive power compensation; however it is capable of neither load balancing nor voltage regulation. Control system design can easily be implemented by using proportionalintegral (PI) controller in such an SVC. This type of control can be seen in Fig.1.8. In order to be able to achieve load balancing, the negative sequence of the load current must be removed entirely.

Reactive current component calculation and reactive power calculations can be evaluated by using 50 $\mathrm{Hz}$ averaging. This method will cause responses in the TCR because $50 \mathrm{~Hz}$ averaging method will require time to take the average value of the signal. 


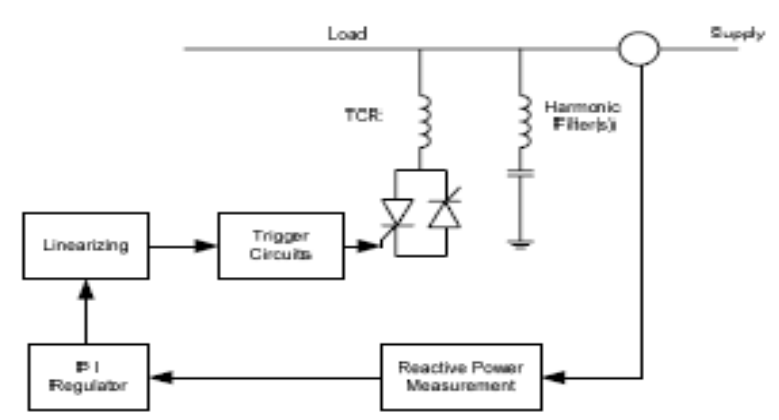

Fig.1.8 Simple reactive power compensation by PI controller

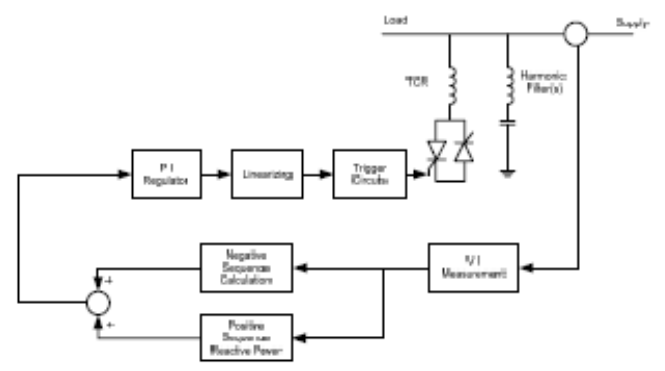

Fig.1.9 Reactive power compensation with load balancing by PI controller

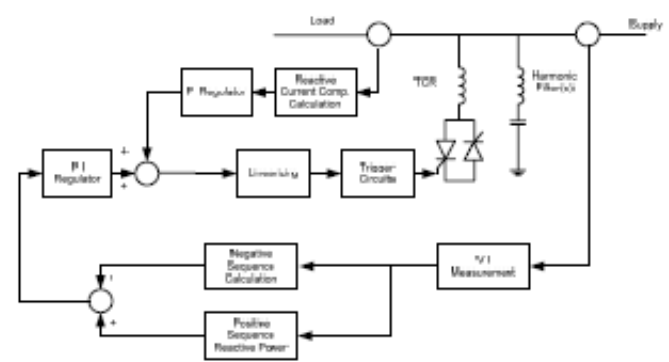

Fig.1.10 Flicker Compensation System with feed-forward and feed-back control

\subsection{Thyristor Valve Control and Misfiring}

Ideal TCR line currents are $90^{\circ}$ displaced from the line voltage and they are symmetrical and balanced if the firing delay angle is in the range of $90^{\circ}-180^{\circ}$ for positive half cycle and $270^{\circ}-360^{\circ}$ in the negative half cycle. These are the safe operating regions of TCR, which are the 2 nd and the 4 th regions shown in Fig.1.11. Whenever the conduction angle of a thyristor exceeds $180^{\circ}$, a DC current component exists. In a non-ideal TCR which includes an internal resistor, the firing delay angle can be reduced below $90^{\circ}$. The exact angle can be calculated from the inductive reactance and the resistance of the TCR.

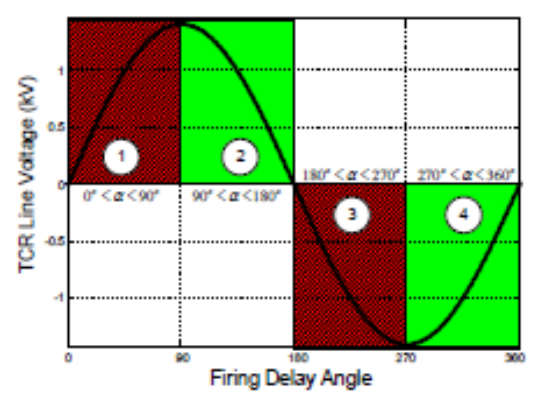

Fig.1.11. Firing Delay Angle $(\alpha)$ versus TCR line voltage. The safe operating regions 2 and 4 of TCR are marked and Unsafe operating regions land 3 are marked.

\section{Conclusion:}

From the implemented tests and procedure, it can be concluded that the design of SVC in transmission lines offers controlling the power flow in an efficient manner. The TCR simulation for a $1 \mathrm{kV} 1,5$ MVAr TCR $+0,75 \mathrm{kVAr}$ Filter installation with a short circuit 525 MVA was tested and shown in this paper 
using PSCAD "Multirun" simulator. In order to be able to achieve load balancing, the negative sequence of the load current must be eliminated completely. Control system design can easily be implemented by using proportional-integral (PI) controller in such an SVC.

\section{References}

[1] T.J.E. Miller, "Reactive Power Control In Electric Systems,”, John Wiley\&Sons, 1982.

[2] J.Arrilaga, N.R. Watson, "Power System Harmonics", Wiley, 1982

[3] "IEEE Guide for the Functional Specification of Transmission Static Var Compensators" IEEE Std 1031-1991)

[4] "IEEE Guide for the Functional Specification of Transmission Static Var Compensators" IEEE Std 1031-2000 (Revision ofIEEE Std 1031-1991)

[5] M.V. Utalay, "Design and Implementation of a Medium Voltage Thyristor Controlled Reactor", MSc. Thesis, METU, Jan.1996

[6] Semikron Power Electronics Catalogue,Semikron Inc. Germany, 10/1998.

[7] Lawatsch, H.M.; Vitins, J.; "Protection of thyristors against overvoltage with breakover diyotes", IEEE Transactions on Industry Applications Volume 24, Issue 3, May-June 1988 pp. 444 - 448

[8] TS 831, "Standard Voltages in THE Distribution Systems", 1979

[9] "Effects of Temperature on Thyristor Performance" Application Note AN4870, Dynex Semiconductors, January 2000.

[10] ANSI/IEEE Std. C37.109, "IEEE Guide for the Protection of Shunt Reactors" 1988

[11] IEEE Std. C57-114, "IEEE Seismic Guide for Power Transformers and Reactors", 1990

[12] IEEE Standard Requirements,Terminology, and Test Code for Shunt Reactors Rated Over 500 kVA, IEEE Std. C57.21-1990

[13] IEEE Std. C57-125, "IEEE Guide for Failure Investigation, Documentation,and Analysis for Power Transformers and Shunt Reactors" 1991

[14] "IEEE Loss Evalution Guide for Power Transformers and Reactors" IEEE Std C57-120-1991

[15] IEC 60289 "Reactors", 1988

[16] IEC 61642 Industrial a.c. Networks Affected by Harmonics - Application of Filters and Shunt Capacitors 